\title{
Etiologia viral das infecções respiratórias agudas em população pediátrica no Instituto Fernandes Figueira/FIOCRUZ/RJ
}

\author{
Viral etiology of acute respiratory infections among children at Instituto Fernandes Figueira/FIOCRUZ/RJ
}

Rosemary Suely Ribeiro'; Maria Virginia Peixoto Dutra²; Laurinda Shinzato Yoko Higa ${ }^{3}$; Urutay Tavares de Oliveira ${ }^{4}$; Paulo Roberto Soares Stephens ${ }^{5}$; Sivana Augusta Rodrigues Portes ${ }^{6}$

unitermos
Infecções respiratórias
agudas
Infecção viral
Criança
Imunofluorescência

\section{resumo}

Introdução: As infecções respiratórias agudas (IRAs) constituem importante causa de morbidade e mortalidade em crianças nos países em desenvolvimento. A etiologia viral dessas infecções nem sempre é conhecida no Brasil, e estudos sobre as IRAs virais em crianças com doenças de base (DBs) são escassos. Objetivo: Determinar a etiologia viral dessas infecções em menores de 5 anos assistidos no Instituto Fernandes Figueira da Fundação Oswaldo Cruz (IFF/FIOCRUZ), Rio de Janeiro. Método: Foram analisadas 285 amostras de aspirado de nasofaringe, obtidas de 204 crianças com IRA, de maio de 2005 a junho de 2006. Resultados: Por meio da imunofluorescência indireta (IFI), 90 amostras (31,6\%) foram positivas: $21,4 \%$ vírus sincicial respiratório (VSR); 3,5\% adenovírus (Ad); 3,1\% parainfluenza (PF) 3; 2,5\% influenza (Flu) A; 0,7\% PF 1; 0,4\% Flu B. Das 195 negativas, 156 foram testadas para metapneumovírus humano (MPVh), com 15 positivas (9,6 \% das amostras testadas). Conclusão: A prevalência viral nos serviços de ambulatórios foi de $42,8 \%$ e nos hospitalizados foi de $30 \%$. Das crianças, $83,3 \%$ possuíam uma ou mais DBs associadas às IRAs, resultando em longos períodos de internação. Algumas delas tiveram múltiplas internações e múltiplos diagnósticos clínicos de IRA no período estudado.

\section{abstract}

Introduction: Acute respiratory infections (ARIs) are an important cause of morbidity and mortality among children in developing countries. The viral etiology of such infections is not always known in Brazil. Furthermore, studies on viral ARIs in children with underlying diseases (UD) are scanty. Objective: The objective of this study was to determine the viral etiology of these infections among children under 5 years of age treated at Instituto Fernandes Figueira/Fundação Oswaldo Cruz (IFF/FIOCRUZ), Rio de Janeiro. Method: Two hundred and eighty-five samples of nasopharyngeal aspirate, which had been obtained from 204 children with ARI from May/2005 to June/2006, were analyzed. Results: Samples were tested through indirect immunofluorescence assay and 90 of them (31.6\%) were positive for the following viral agents: respiratory syncytial virus (21.4\%), adenovirus (3.5\%), parainfluenza $3(3.1 \%)$, influenza $A(2.5 \%)$, parainfluenza 1 $(0.7 \%)$, and influenza $B(0.4 \%)$. One hundred and ninety-five samples were negative, from which 156 were tested for human metapneumovirus, and 15 of them (9.6\%) were positive. Conclusion: The viral prevalence among outpatients was $42.8 \%$ and among inpatients it was $30 \% ; 83.3 \%$ of the children were carriers of one or more UD associated with ARI, resulting in long-term admission to hospital. Some children had multiple admissions and multiple clinical diagnoses of ARI during the studied period.

\section{key words}

Acute respiratory infections

Viral infection

Children

Imunofluorescence

1. Mestra em Saúde da Criança e da Mulher pelo Instituto Fernandes Figueira da Fundação Oswaldo Cruz (IFF/FIOCRUZ); farmacêutica e bioquímica do IFF/FIOCRUZ.

2. Doutora em Ciência em Engenharia Biomédica pela Universidade Federal do Rio de Janeiro (UFR)); pesquisadora do IFF/FIOCRUZ.

3. Mestra em Saúde da Criança e da Mulher pelo IFF/FIOCRUZ; médica do IFF/FIOCRUZ.

4. Mestre em Saúde da Criança e da Mulher pelo IFF/FIOCRUZ; técnico em Saúde Pública do IFF/FIOCRUZ.

5. Mestre em Microbiologia pela UFRI; pesquisador adjunto do Instituto Oswaldo Cruz (IOC)/FIOCRUZ.

6. Mestra em Biologia Molecular pela FIOCRUZ; pesquisadora adjunta do IOC/FIOCRUZ. 


\section{Introdução}

As infecções respiratórias agudas (IRAs) constituem um problema de saúde pública para as crianças em todo o mundo, em particular nos países em desenvolvimento, onde a morbidade e a mortalidade apresentam índices mais altos que nos países desenvolvidos ${ }^{(4)}$. No Brasil, as IRAs respondem por $30 \%$ a $60 \%$ das consultas ambulatoriais a menores de 5 anos. Em 1999, as pneumonias e outras IRAs representaram $35 \%$ do total de internações no sistema público de saúde, com custo correspondente a $31 \%$ do total gasto com crianças desse grupo etário(1).

Os vírus são os agentes etiológicos responsáveis pela maior parte dos casos de IRA. A maioria das infecções é branda, autolimitada e envolve o trato respiratório superior $^{(5)}$. Entretanto, os vírus são considerados os mais importantes agentes etiológicos das infecções do trato respiratório inferior que requerem hospitalizações ${ }^{(17)}$. Entre os mais frequentes agentes virais causadores de IRA estão o vírus sincicial respiratório (VSR), os adenovírus (Ad), os vírus influenza (Flu) $A$ e $B$ e os vírus parainfluenza (PF) 1, 2 e $3^{(11,17,18)}$. O metapneumovírus humano (MPVh) também tem se mostrado importante agente causador de bronquiolite aguda em crianças $^{(38)}$.

As IRAs virais são especialmente graves em crianças com doenças cardíacas, pulmonares crônicas e imunodeficiências $^{(15,37)}$. Sequelas pulmonares relevantes podem resultar dessas infecções, sendo importante a determinação da etiologia viral para o conhecimento da prevalência de cada um desses agentes ${ }^{(33)}$.

A detecção de vírus respiratório mediante diagnóstico laboratorial rápido é um imprescindível instrumento, que possibilita atuar na redução da prescrição desnecessária de antibióticos nos indivíduos pediátricos ${ }^{(6)}$, na implementação de terapias antivirais em casos específicos e na diminuição dos dias de hospitalização(2).

A imunofluorescência (IF) consiste em um método simples e de fácil aplicação e é bastante utilizada para fins de diagnóstico ou pesquisa. Foi um dos primeiros métodos a permitir um diagnóstico viral rápido, o que é relevante, tendo impacto substancial na virologia e na clínica ${ }^{(16)}$. O diagnóstico laboratorial das IRAs virais não é amplamente realizado no Brasil, e estudos brasileiros não descrevem a associação dessas infecções a outras doenças de base (DBs).

O objetivo deste estudo foi determinar a etiologia viral das infecções respiratórias agudas nas crianças assistidas no Instituto Fernandes Figueira da Fundação Oswaldo Cruz (IFF/FIOCRUZ), no Rio de Janeiro, descrevendo a distribuição sazonal dos vírus no período proposto, os aspectos demográficos e clínicos e as principais associações das IRAs virais a outras DBs.

\section{Materiais e métodos}

\section{Tipo e período do estudo}

Estudo transversal descritivo no qual foram avaliados dados referentes à demanda hospitalar no período de maio de 2005 a junho de 2006.

\section{Pacientes e local do estudo}

Foram incluídas crianças menores de 5 anos com no máximo sete dias do início dos sintomas de IRA, atendidas nos ambulatórios e na unidade de pacientes hospitalizados: enfermarias, unidade de cuidados intermediários (UI), unidade de pacientes graves (UPG), berçários dos departamentos de Pediatria, Neonatologia e Cirurgia Pediátrica do IFF.

O IFF é uma unidade técnico-científica da FIOCRUZ, situado na cidade do Rio de Janeiro e vinculado ao Ministério da Saúde. $\mathrm{O}$ atendimento é feito por meio de consultas periódicas previamente agendadas nos ambulatórios e nas unidades de pacientes hospitalizados, que também recebem a demanda externa referida de hospitais e unidades básicas de saúde. O IFF não dispõe de serviço de emergência.

Como se trata de um serviço de referência é frequente o achado de morbidade(s) prévia(s) nas crianças assistidas, o que motivou seu agrupamento em relação à presença de DBs como uma variável do estudo. Definiu-se como DB as crônicas prévias, congênitas ou não. $O$ critério de seleção para a escolha da DB a ser demonstrada na análise foi sua gravidade e a associação como fator de risco para o desenvolvimento de doenças respiratórias graves. Os grupos foram constituídos por pacientes sem DB, com histórico de prematuridade, cardiopatias congênitas, doenças pulmonares crônicas e outras DBs. No grupo de outras DBs foram incluídas imunodeficiências, encefalopatias, de forma isolada ou associada à hidrocefalia, síndromes genéticas e malformações que necessitaram procedimento cirúrgico, como atresia de esôfago, refluxo gastroesofágico, intestino curto e outras doenças menos frequentes. As DBs foram classificadas de acordo com a décima revisão da Classificação Estatística Internacional de Doenças e Problemas Relacionados à Saúde (CID-10)(22).

O diagnóstico das IRAs foi feito em bases clínicas e, quando necessário, complementado com a radiografia de 
tórax. Quando houve suspeita da etiologia viral, a coleta do aspirado de nasofaringe (ANF) foi realizada na consulta ou na hospitalização. Dados referentes a idade, sexo, residência, diagnóstico clínico, dias de início dos sintomas, local de atendimento e DBs foram obtidos no momento da coleta do ANF; aqueles referentes a dias e número de internações e óbitos foram obtidos mediante consultas aos prontuários e ao arquivo nosológico. As variáveis que se modificavam a cada coleta de ANF (diagnóstico clínico, local de atendimento, idade, vírus detectado e mês de detecção) foram analisadas por amostras; as demais (sexo, residência e DBs), que não se modificavam ao longo do estudo, foram analisadas por indivíduo. Definiu-se como evento de IRA o diagnóstico clínico da infecção com correspondente coleta do ANF para análise.

O estudo foi aprovado pelo Comitê de Ética em Pesquisa (CEP) com Seres Humanos do IFF/FIOCRUZ/RJ.

\section{Coleta, transporte e processamento das amostras}

As secreções de nasofaringe foram obtidas por aspiração, introduzindo uma sonda cirúrgica siliconizada $\mathrm{n}^{\circ} 6 \mathrm{em}$ uma ou em ambas as narinas, conectada a uma seringa descartável(13), e processadas, conforme descrito por Gardner e McQuillin ${ }^{(12)}$. Foram refrigeradas a $4^{\circ} \mathrm{C}$ e enviadas ao Laboratório de Virologia do Departamento de Patologia Clínica e Pesquisa do IFF.

Foi utilizado o kit Biotrin Respiratory Viral Panel (Irlanda) para a pesquisa de Ad, Flu A e B, PF 1, 2 e 3 e VSR pela técnica de imunofluorescência indireta (IFI), seguindo instruções do fabricante e anti-MPV 751 clone 1 B7 contra M1 proteína do MPVh (cat MAB 8510- Chemicon).

\section{Análise estatística}

As variáveis contínuas foram apresentadas e resumidas por medidas de tendência central e dispersão, e as variáveis categóricas foram apresentadas por meio de proporções. As diferenças foram testadas pelo qui-quadrado, com correção de Yates, quando necessário, e pelo teste exato de Fisher, com nível de significância de $5 \%$. Todos os procedimentos com os bancos e análise dos dados foram executados pelos programas EPIINFO $2000^{\circledR}$ e Excel $^{\oplus}$.

\section{Resultados}

No período de abril de 2005 a junho de 2006 foram analisadas 285 amostras de ANF coletadas de 204 crianças com IRA atendidas nos ambulatórios e nas unidades de pacientes hospitalizados. A maioria das crianças era do sexo masculino $(55,8 \%)$.

A média de idade entre elas foi de 11,8 meses, com desvio padrão (DP) de 11,4 meses e a mediana de 8,3 meses (mínimo de 8 dias e máximo de 4 anos e 11 meses). A média de dias de internação foi de 26 ( $D P=35$ dias) e a mediana de 14 (mínimo de um dia e máximo de 275). O número médio de internações por criança foi 1,7, com o mínimo de uma e o máximo de seis internações no período estudado. Todas as crianças residiam no estado do Rio de Janeiro e, destas, $91 \%$ eram da região Metropolitana 1, sendo $60 \%$ do município do Rio de Janeiro e 31\% de outros municípios, principalmente da Baixada Fluminense. Os 9\% restantes residiam em municípios das demais regiões do estado.

Entre as crianças estudadas, 58\% apresentaram apenas um evento de IRA; em $18 \%$ foram identificados dois eventos e em $24 \%$, de três a nove eventos.

As amostras oriundas dos ambulatórios representaram somente $12,3 \%$ (35/285) do total coletado. Observou-se o predomínio de infecções das vias aéreas inferiores (IVAls) $(60,7 \%)$ sobre as infecções das vias aéreas superiores (IVASs) (39,3\%). As IVASs foram diagnosticadas em 83,3\% (15/18) dos pacientes atendidos nos berçários e em 57,1\% (20/35) daqueles em ambulatórios, enquanto as IVAls foram mais diagnosticadas nos pacientes hospitalizados; nas enfermarias, $63,5 \%(127 / 200)$ e na UPG, $87,5 \%$ (28/32).

Ao realizar a pesquisa dos vírus respiratórios pela técnica da IFI, foi detectado um vírus por amostra em 31,6\% (90/285) dos ANFs. Em ordem decrescente de prevalência, detectou-se o VSR em 21,4\% (61/285), Ad em 3,5\% (10/285), PF 3 em 3,1\% (09/285), Flu A em 2,5\% (07/285), PF 1 em 0,7\% (2/285) e Flu B em 0,4\% (1/285). Não foi detectado PF 2. A relação entre os diagnósticos clínicos e os vírus respiratórios identificados pode ser observada na Tabela 1. Das 195 amostras negativas, 156 foram posteriormente testadas por IFI para MPVh com $9,6 \%$ de positividade (15/156). A análise estatística demonstrou que houve predomínio com significância estatística das IVAls sobre as IVASs, produzidas pelo VSR $(p=0,036)$, o mesmo não ocorreu para os outros vírus respiratórios agrupados $(p=0,506)$.

Das amostras estudadas, cerca de $70 \%$ eram referentes a crianças menores de 1 ano. A distribuição dos vírus respiratórios detectados por faixa etária, segundo diagnóstico clínico, está representada na Tabela 2. Verificou-se a detecção do VSR em todas as faixas etárias, predominando no primeiro ano de vida. O Ad foi mais frequente na faixa 
Vírus respiratórios identificados segundo diagnóstico clínico de IRA em 285 amostras de ANF de Tabela 1 crianças assistidas no IFF/FIOCRUZ/RJ, no período de maio de 2005 a junho de 2006

\begin{tabular}{|l|c|c|c|c|c|c|c|c|}
\hline \multirow{2}{*}{ Diagnóstico clínico } & VSR & Ad & PF 3 & Flu A & PF 1 & Flu B & $\begin{array}{c}\text { Total de amostras } \\
\text { positivas }\end{array}$ & $\begin{array}{c}\text { Total de } \\
\text { amostras }\end{array}$ \\
\cline { 2 - 10 } & $n \%$ & $n \%$ & $n \%$ & $n \%$ & $n \%$ & $n \%$ & $n \%$ & $n \%$ \\
\hline \multirow{2}{*}{ IVAS } & 9 & 5 & 5 & 2 & 2 & 1 & 24 & 112 \\
\hline \multirow{2}{*}{ IVAI } & 14,8 & 50 & 55,6 & 28,6 & 100 & 100 & 26,7 & 39,3 \\
\hline \multirow{2}{*}{ Total $n \%$} & 52 & 5 & 5 & 5 & - & - & 66 & 173 \\
\hline
\end{tabular}

IRA: infecção respiratória aguda; ANF: aspirado de nasofaringe; IFF/FIOCRUZ: Instituto Fernandes Figueira da Fundação Oswaldo Cruz; VSR: vírus sincicial respiratório; Ad: adenovírus; PF 1 e 3: vírus parainfluenza 1 e 3; Flu A e B: vírus influenza A e B; IVAS: infecção das vias aéreas superiores; IVAl: infecção das vias aéreas inferiores.

\section{Vírus respiratórios identificados segundo a faixa etária das crianças menores de 5 anos com IRA} Tabela 2 assistidas no IFF/FIOCRUZ/RJ, no período de maio de 2005 a junho de 2006

\begin{tabular}{|c|c|c|c|c|c|}
\hline \multirow{2}{*}{$\begin{array}{l}\text { Vírus/idade } \\
\text { (meses) }\end{array}$} & VSR & $\mathrm{Ad}$ & PF 1 e 3 & Flu A e B & $\begin{array}{l}\text { Total de positivos/ } \\
\text { total de amostras }\end{array}$ \\
\hline & $n \%$ & $n \%$ & $n \%$ & $n \%$ & $n(\%)$ \\
\hline$\leq 3$ & $\begin{array}{c}17 \\
27,9\end{array}$ & $\begin{array}{c}1 \\
10\end{array}$ & $\begin{array}{c}5 \\
45,4\end{array}$ & $\begin{array}{c}2 \\
25\end{array}$ & $\begin{array}{c}25 / 52 \\
(48)\end{array}$ \\
\hline$>3-6$ & $\begin{array}{c}20 \\
32,8\end{array}$ & $\begin{array}{c}1 \\
10\end{array}$ & 0 & $\begin{array}{c}1 \\
12,5\end{array}$ & $\begin{array}{l}22 / 57 \\
(38,6)\end{array}$ \\
\hline$>6-9$ & $\begin{array}{c}7 \\
11,5\end{array}$ & 0 & $\begin{array}{c}1 \\
9,1\end{array}$ & $\begin{array}{c}1 \\
12,5\end{array}$ & $\begin{array}{l}9 / 50 \\
(18)\end{array}$ \\
\hline$>9-12$ & $\begin{array}{c}6 \\
9,8\end{array}$ & $\begin{array}{c}1 \\
10\end{array}$ & $\begin{array}{c}3 \\
27,3\end{array}$ & $\begin{array}{c}1 \\
12,5\end{array}$ & $\begin{array}{l}11 / 34 \\
(32,3)\end{array}$ \\
\hline$>12-24$ & $\begin{array}{c}6 \\
9,8\end{array}$ & $\begin{array}{c}6 \\
60\end{array}$ & $\begin{array}{c}1 \\
9,1\end{array}$ & $\begin{array}{c}2 \\
25\end{array}$ & $\begin{array}{l}15 / 58 \\
(25,9)\end{array}$ \\
\hline$>24-60$ & $\begin{array}{c}5 \\
8,2\end{array}$ & $\begin{array}{c}1 \\
10\end{array}$ & $\begin{array}{c}1 \\
9,1\end{array}$ & $\begin{array}{c}1 \\
12,5\end{array}$ & $\begin{array}{c}8 / 34 \\
(23,5)\end{array}$ \\
\hline Total $n \%$ & $\begin{array}{c}61 \\
100\end{array}$ & $\begin{array}{c}10 \\
100\end{array}$ & $\begin{array}{c}11 \\
100\end{array}$ & $\begin{array}{c}8 \\
100\end{array}$ & $\begin{array}{c}90 / 285 \\
(31,6)\end{array}$ \\
\hline
\end{tabular}

IRA: infecção respiratória aguda; IFF/FIOCRUZ: Instituto Fernandes Figueira da Fundação Oswaldo Cruz; VSR: vírus sincicial respiratório; Ad: adenovírus; PF 1e 3: vírus parainfluenza 1 e 3; Flu $A$ e $B$ : vírus influenza $A$ e $B$.

etária de 1 a 2 anos. Quanto aos PF 1 e 3, foram mais detectados na faixa inferior a 3 meses, seguida da faixa de 9 a 12 meses de idade. Os Flu A e B distribuíram-se em todas as faixas etárias.

Das amostras positivas, $51,1 \%$ (46/90) eram de crianças do sexo masculino e $48,9 \%$ (44/90), de crianças do sexo feminino.
A Figura 1 demonstra a distribuição mensal das IRAs e dos vírus identificados no período proposto. Verificou-se a ocorrência dos eventos de IRA em todos os meses do ano. A maior detecção viral aconteceu nos meses de outono (abril, maio e junho), seguindo-se nos meses de inverno (julho e agosto).

As crianças com DBs compreenderam $83,3 \%$ (170/204) do total de crianças estudadas, das quais $20 \%$ 
(34/170) apresentavam uma DB e $80 \%(136 / 170)$, duas ou mais DBs associadas. As relações entre pacientes, eventos de IRA e positividade, segundo a principal DB associada, estão demonstradas na Figura 2. A identificação viral nas crianças sem DBs foi de 44,7\% (17/38). A proporção da identificação viral variou segundo a categoria de $D B, 41,6 \%(10 / 24)$ na prematuridade; $34,3 \%$ (12/35) nas cardiopatias congênitas; 35,2\% (25/71) nas doenças pulmonares crônicas; $22,2 \%$ (26/117) nas outras doenças.

Entre as crianças que apresentaram mais de um evento de IRA no período estudado (42\%), em cinco delas houve a identificação de vírus em dois episódios de IRA. Dois pacientes tinham doença pulmonar crônica, dois eram prematuros e um era prematuro com cardiopatia congênita. Os vírus detectados pelo indivíduo com o correspondente

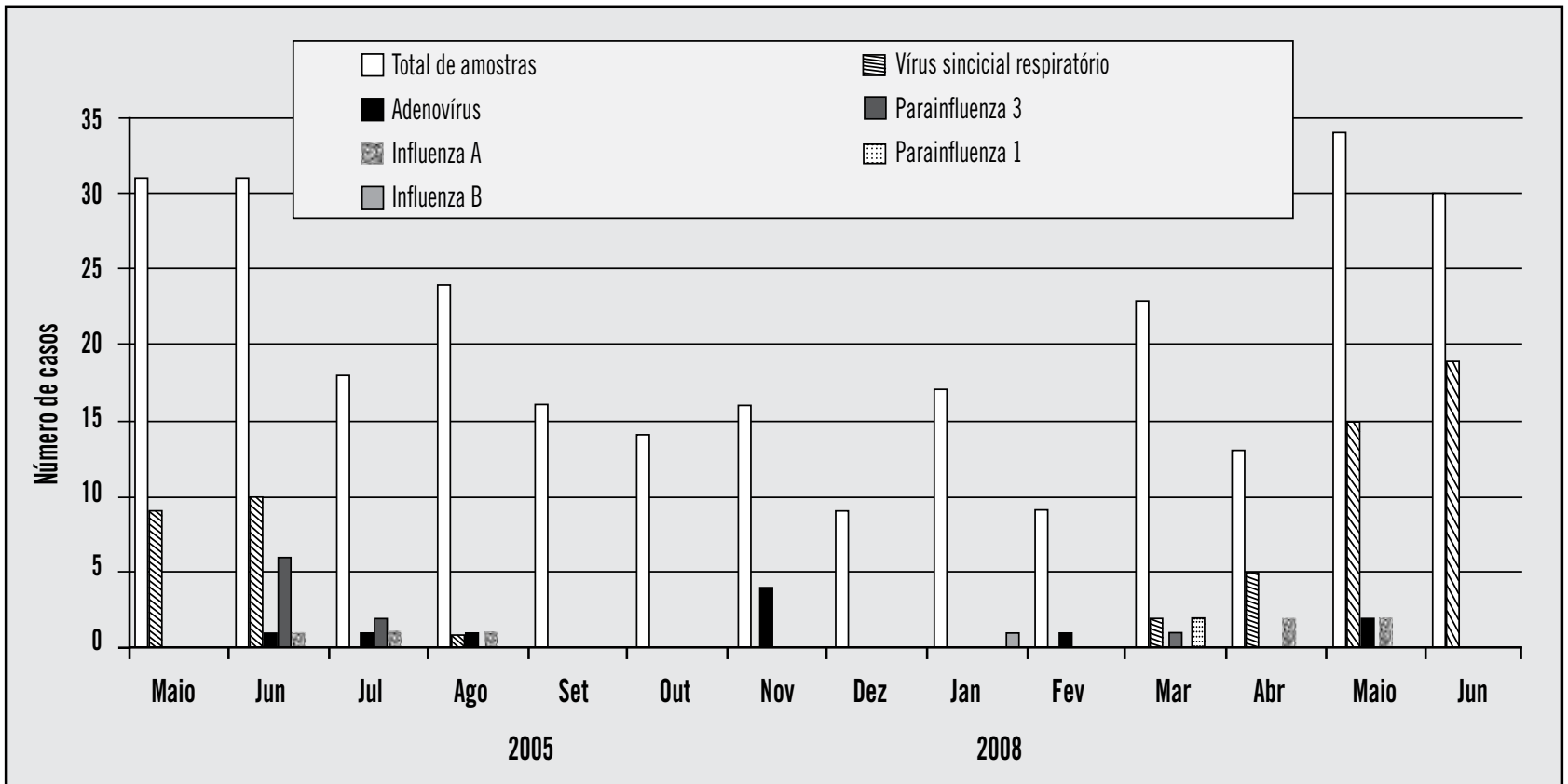

Figura 1 - Vírus respiratórios identificados em 285 secreções de nasofaringe de crianças com IRA assistidas no IFF/FIOCRUZ/RJ, no período de maio de 2005 a junho de 2006 IRA: infecção respiratória aguda; IFF/FIOCRUZ/RJ: Instituto Fernandes Figueira da Fundação Oswaldo Cruz.

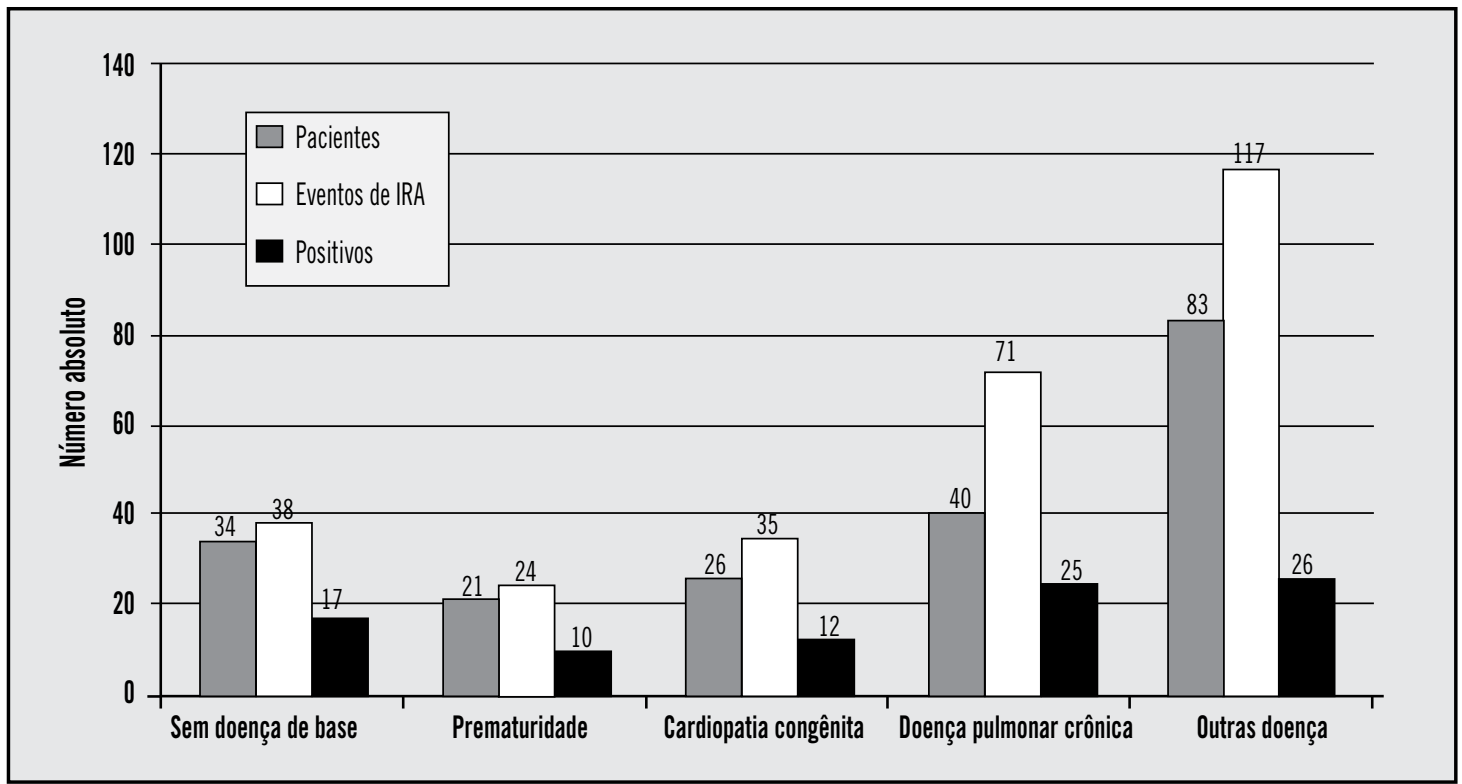

Figura 2 - Relação entre pacientes, amostras e detecção viral segundo presença ou não de DB em crianças menores de 5 anos com IRA assistidas no IFF/FIOCRUZ/RJ, no período de maio de 2005 a junho de 2006

DB: doença de base; IRA: infecção respiratória aguda; IFF/FIOCRUZ/RJ: Instituto Fernandes Figueira da Fundação Oswaldo Cruz. 
intervalo entre as detecções foram os seguintes: Flu A e Ad (95 dias), PF 3 e Ad (119 dias), Ad e VSR (174 dias), VSR e VSR (61 dias e oito dias).

Das crianças envolvidas no estudo, sete evoluíram para óbito e em duas delas houve detecção viral. Em um lactente de 5 meses de idade com cardiopatia congênita, internado por bronquiolite e pneumonia, foi detectado VSR oito dias antes do óbito. Em outro lactente de 10 meses de idade com doença pulmonar crônica, internado por bronquiolite, foi detectado PF 313 dias antes do óbito.

\section{Discussão}

A detecção dos agentes virais foi realizada mediante técnica de IFI devido a rapidez, facilidade diagnóstica e possibilidade de detecção de coinfecções virais em uma mesma amostra. Ao utilizar como única técnica diagnóstica a IFI, a detecção de vírus respiratórios nas amostras estudadas foi 31,6\% (90/285). Resultados parecidos para os mesmos vírus foram obtidos por Stralioto et al. ${ }^{(30)}(36,6 \%)$ e Moura et al. ${ }^{(18)}(31,9 \%)$ em populações semelhantes. Estudos demonstram que IF, associada ao isolamento viral em cultura de células, pode aumentar a detecção viral ${ }^{(18,36)}$. Perfeita concordância entre os resultados obtidos pelas duas técnicas foi demonstrada por Miyao et al.(17), atribuída a adequada padronização de técnicas e coleta, transporte e processamento das amostras.

Os resultados obtidos por diferentes estudos dependem de técnicas utilizadas, época do ano e idade da população estudada, diagnóstico clínico, dias de início dos sintomas, qualidade do espécime biológico utilizado, entre outros.

A ocorrência das IRAs não foi diferente entre os sexos, o que sugere similaridade na prevalência de infecções virais entre eles, também observado pelos autores Sutmoller et al. e Moura et al. ${ }^{(18,32)}$.

O VSR foi detectado principalmente durante o outono, conforme reportado por Nascimento et al.(19) em estudo de quatro anos consecutivos no Rio de Janeiro. Outros trabalhos na região Sudeste, nas cidades de Uberlândia ${ }^{(11)} \mathrm{e}$ Vitória ${ }^{(10)}$, reportaram a ocorrência do VSR no final do verão e durante o outono, assim como nos meses chuvosos, março a julho, em Salvador ${ }^{(18)}$. Em cidades com temperaturas mais baixas durante o inverno, como São Paulo ${ }^{(36)}$ e Porto Ale$\mathrm{gre}^{(30)}$, o VSR é mais detectado nos meses de julho e agosto. O Ad se apresenta com baixa frequência em vários meses do estudo, conforme reportado por Moura et al. ${ }^{(18)}$. O PF 3 foi o vírus mais detectado entre os PF, com maior ocorrência no mês de junho. Outros estudos atribuíram maior ocorrência desse vírus no segundo semestre do ano ${ }^{(18,19)}$. Ocorreram apenas dois casos de PF 1 e nenhum de PF 2, mas o período estudado não foi suficiente para confirmar a ocorrência desses vírus em ciclos bianuais ${ }^{(35)}$. A baixa sensibilidade da IF na detecção de PF $2^{(14)}$ também pode justificar a não identificação desse vírus na população estudada. Os Flu, principalmente $\mathrm{o}$, se apresentaram com baixa frequência em cinco meses do estudo; em quatro deles foi observada sua circulação em concomitância com o VSR ${ }^{(21)}$.

$\mathrm{O}$ atendimento emergencial fornece mais informações sobre a variação sazonal de IRAs e agentes virais associados a IVASs na infância ${ }^{(19)}$. O presente estudo descreveu a distribuição das IRAs virais nos pacientes atendidos nos ambulatórios e hospitalizados no IFF, em um período de 14 meses, não gerando dados suficientes para discussão da distribuição sazonal dos vírus respiratórios no Rio de Janeiro.

Por não haver atendimento de emergência no IFF, a maioria dos indivíduos estudados estava hospitalizada e os demais tiveram o diagnóstico clínico de IRA em consultas previamente agendadas. O pequeno número de eventos de IRA investigados em pacientes ambulatoriais (35) não constituiu uma amostra representativa do total de atendimentos ambulatoriais de crianças com IRA no IFF. A prevalência de agentes virais nos atendimentos ambulatoriais foi de $42,8 \%$ (15/35), semelhante à prevalência viral de 40,5\% obtida no ano de 1991 por Straliotto et al. ${ }^{(30)}$, em população numericamente semelhante à de crianças assistidas nos ambulatórios. O VSR foi o vírus mais detectado, seguido do Ad, em ambos os estudos.

Entre as crianças hospitalizadas com diagnóstico de IRA das vias aéreas superiores e inferiores, houve $30 \%$ de detecção viral, com percentuais de $21,7 \%$ e $34,8 \%$, respectivamente. Straliotto et al. ${ }^{(29,30)}$ obtiveram as detecções de $28,7 \%$ e $42,3 \%$ em crianças hospitalizadas com IVAl. Miyao et al. ${ }^{(17)}$ obtiveram $56,4 \%$ de positividade em estudo com crianças hospitalizadas com IVAI no período de maior ocorrência viral.

As infecções pelo VSR que resultaram em hospitalização acometeram principalmente crianças com até 6 meses de idade, o mesmo foi observado em outros estudos ${ }^{(19,29,36)}$. Nas faixas etárias de 7 meses a 1 ano e de 1 a 2 anos, a associação do VSR às hospitalizações diminuiu consecutivamente. O VSR foi detectado em $21 \%$ do total das amostras e foi o principal agente etiológico das IRAs virais em crianças menores de 5 anos, resultado próximo de 17,5\% encontrado por Moura et al. ${ }^{(18) ;} 24 \%$, por Calegari et al.(8) e $26,2 \%$, por Straliotto et al. ${ }^{(30)}$. 
O período médio de excreção do VSR em crianças é de nove dias, mas bebês podem excretar o vírus em até três semanas após o início dos sintomas ${ }^{(23)}$. O caso em que o VSR foi detectado em duas amostras de um paciente com menos de 3 meses de idade, prematuro, com cardiopatia congênita, provavelmente foi uma única infecção que pode ter agravado, pois a primeira detecção ocorreu no momento em que a criança estava internada na UI e a segunda detecção, oito dias após, na UPG.

Os Ad apresentaram prevalência inversa à do VSR, elevando essa prevalência com o aumento da faixa etária, estando mais associado às IRAs na faixa de 1 a 2 anos, resultados também obtidos por Straliotto et al. ${ }^{(30)}$. Embora estudos demonstrem baixa sensibilidade da IF na detecção de $\mathrm{Ad}^{(14,27)}$, este foi um dos vírus mais detectados nos ambulatórios e pacientes hospitalizados, concordando com Nascimento et al. ${ }^{(19)}$, Miyao et al. ${ }^{(17)}$ e Vieira et al. ${ }^{(36)}$, e acometeu igualmente vias aéreas superiores e inferiores, semelhante ao estudo de Moura et al.(18).

Os PF foram detectados entre os indivíduos hospitalizados. Foi o terceiro vírus mais detectado e com maior ocorrência na faixa de até 1 ano de idade, semelhante ao observado em estudo realizado no Rio de Janeiro(19).

Importante associação do Flu à IRA tem sido demonstrada em estudos realizados com crianças assistidas em ambulatórios e/ou emergências ${ }^{(11,18,30)}$, o que não é observado entre aquelas hospitalizadas ${ }^{(17,18,30,36)}$, nas quais o Flu é pouco detectado. Entre os vírus pesquisados, o Flu foi o menos detectado, acometendo, principalmente, as crianças hospitalizadas com menos de 2 anos com IVAI.

O MPVh é o mais recente vírus respiratório isolado de ANF e foi mais detectado nas crianças hospitalizadas com IVAI. A detecção de MPVh, observada também em outros trabalhos $(3,9,28,38)$, demonstra a importância desse vírus como agente etiológico das IRAs pediátricas que requerem hospitalização.

Infecções simultâneas com dois ou mais patógenos virais, bacterianos ou ambos vêm sendo demonstradas em diferentes pesquisas ${ }^{(7,26)}$. Coinfecções virais foram detectadas nos estudos de Tsuchiya et al.(.4) e Moura et al.(18). Assim, como descrito por Myiao et al..$^{(17)}$ e Costa et al..$^{(11)}$, não detectamos coinfecções virais neste estudo.

Dois óbitos com etiologia viral comprovada (VSR e PF 3) podem ter ocorrido devido a outros fatores de risco, pois os resultados da autópsia não foram disponibilizados, mas ambos aconteceram em duas semanas após o diagnóstico viral, período arbitrado por Navas et al. ${ }^{(20)}$ para a associação de VSR aos óbitos em seu estudo. Entre os indivíduos que apresentaram dois ou mais eventos de IRA, em cinco pacientes foram detectados agente etiológico viral em dois eventos. Nos demais eventos, a ausência de detecção viral pode ter sido devido a limitações técnicas ou características clínicas da DB, podendo ter mimetizado um quadro semelhante ao de uma IRA viral. O grupo de indivíduos sem DB seguido do grupo de pacientes com histórico de prematuridade apresentaram os menores números de eventos de IRA por paciente e os maiores percentuais de detecção viral, provavelmente devido à maior precisão do diagnóstico clínico nesses indivíduos. Entre os pacientes com DB, aqueles com cardiopatias congênitas e doenças pulmonares crônicas tiveram percentuais de detecção viral semelhantes (34,5\% e $35 \%$, respectivamente). No entanto, os doentes pulmonares crônicos mostraram maior número de eventos de IRA por paciente $(1,8)$ do grupo com DB e o menor percentual de detecção viral, que pode se associar à dificuldade em discriminar os sintomas de IRA viral nesses indivíduos. A vigilância intensa em torno desses pacientes, com internações prolongadas em decorrência do tratamento de DBs, também pode explicar o elevado número de coletas de ANF por indivíduo e sem detecção viral.

Além dos agentes etiológicos estudados, outros vírus têm sido associados às doenças respiratórias. Os rinovírus têm sido reportados como importantes agentes etiológicos de bronquiolites e pneumonias em crianças menores de 5 anos ${ }^{(11,24)}$. Estudos de Portes et al. ${ }^{(25)}$, Nascimento et al. ${ }^{(19)}$ e Sutmoller et al. ${ }^{(31,32)}$ demonstraram a associação dos herpesvírus e enterovírus (coxsackie e echovirus) às doenças respiratórias. Outras técnicas diagnósticas, como isolamento viral em culturas celulares, técnica padrão-ouro e reação em cadeia da polimerase (PCR), não foram utilizadas, limitando tecnicamente essa pesquisa. Estudos adicionais são necessários para a identificação de outros vírus não pesquisados, incorporando essas técnicas diagnósticas e elucidando maior número de infecções respiratórias de etiologia viral.

Determinar a etiologia viral das IRAs por meio de IFI é muito importante para o monitoramento dos pacientes, especialmente daqueles com DBs associadas. A maioria das crianças estudadas apresentou DBs associadas às IRAs, o que resultou em longos períodos de internação e em múltiplas internações para algumas crianças. Ocorreram diversos diagnósticos clínicos de IRA sem detecção viral, provavelmente devido a menor precisão do diagnóstico clínico em crianças com DBs, limitações técnicas do estudo ou envolvimento de outros agentes etiológicos não pesquisados. 


\section{Referências}

1. A saúde no Brasil. Documento preparado pela Representação da OPAS no Brasil, em junho de 2001, para subsidiar a elaboração de La Salud en las Américas, edición de 2002 (Publicación Científica y Técnica n 587da OPAS). Disponível em: <http://www.opas.org.br>. Acesso em: 02 jun. 2006.

2. ADCOCK, P. M. et al. Effect of rapid viral diagnosis on the management of children hospitalized with lower respiratory tract infection. Pediatr linfect Dis J, v. 16, n. 9, p. 842-6, 1997.

3. ANDRADE, J. S. R. et al. Metapneumovirus infection among pediatric patients with acute respiratory infection in Rio de Janeiro during 2005-2006. J Braz Soc Virol, v. 11, p. 171, 2006.

4. BENGUIGUI, Y. Acute respiratory infections control in the context of de IMCl strategy in Americas. Rev Bras Saúde Matern Infantil, v. 3, n. 1, p. 25-36, 2003.

5. BERMAN, S. Epidemiology of acute respiratory infections in children of developing countries. Rev Infect Dis, v. 13, Suppl 6, p. 454-62, 1991.

6. BYINGTON, C. L. et al. The effect of rapid respiratory viral diagnostic testing on antibiotic use in a children's hospital. Arch Pediatr Adolesc Med, v. 156, p. 1230-4, 2002.

7. CABELLO, C. et al. Frequency of viruses associated with acute respiratory infections in children younger than five years of age at a locality of Mexico City. Mem Inst Oswaldo Cruz, v. 101, n. 1, p. 21-4, 2006.

8. CALEGARI, T. et al. Clinical-epidemiological evaluation of respiratory syncytial virus infection in children attended in a public hospital in Midwestern Brazil. Brazil J Infect Dis, v. 9, n. 2, p. 156-61, 2005.

9. CHANO, F. et al. Epidemiological survey of human metapneumovírus infection in a large pediatric tertiary care center. J Clin Microbiol, v. 43, n. 11, p. 5520-2, 2005.

10. CHECON, R. E. et al. Short report: seasonal pattern of respiratory syncytial virus in a region with a tropical climate in southeastern Brazil. Am J Med Hyg, v. 67, n. 5, p. 490-1, 2002.

11. COSTA, L. F. et al. Respiratory viruses in children younger than five years old with acute respiratory disease from 2001 to 2004 in Uberlândia, MG, Brazil. Mem Inst Oswaldo Cruz, v. 101, n. 3, p. 301-6, 2006.

12. GARDNER, P. S.; MCQUILLIN, J. Rapid virus diagnosis. Aplication of immunofluorescence. 2. ed. London: Buttterworth, 1980.

13. HARMON, M. W.; KENDAL, A. P. Influenza viruses. In: SCHMIDT, N. J.; EMMONS, R. W. (Ed.). Diagnostic procedures for viral, rickettsial and chlamydial infections. 6. ed. Washington: American Public Health Association, 1989. p. 631-68.

14. IRMEN, K. E.; KELLEHER, J. J. Use of monoclonal antibodies for rapid diagnosis of respiratory viruses in a community hospital. Clin Diagn Lab Immunol, v. 7 , n. 3, p. 396-403, 2000.

15. MACDONALD, N. E. et al. Respiratory syncytial viral infection in infants with congenital heart disease. N Engl J Med, v. 307, n. 7, p. 397-400, 1982.
16. MADELEY, C. R.; PEIRIS, J. S. M. Methods in virus diagnosis: immunofluorescence revisited. J Clin Virol, v. 25, p. 121-34, 2002.

17. MIYAO, C. R. et al. Infecções virais em crianças internadas por doença aguda do trato respiratório inferior. J Pediatr, v. 75, n. 5, p. 334-44, 1999.

18. MOURA, F. E. A. et al. Hospital study of acute respiratory infections in children of Northest Brazil. Jornal Brasileiro de Patologia Clínica, v. 39, n. 4, p. 275-82, 2003.

19. NASCIMENTO, J. P. et al. Longitudinal study of acute respiratory diseases in Rio de Janeiro: occurrence of respiratory viruses during four consecutive years. Rev Inst Med Trop São Paulo, v. 33, n. 4, p. 287-96, 1991.

20. NAVAS, L. et al.; Pediatric Investigators Collaborative Network on Infections in Canada. Improved outcome of respiratory syncytial vírus infection in a high-risk hospitalized population of Canadian children. J Pediatr, v. 121, n. 3, p. 348-54, 1992.

21. NEUZIL, M. K. et al. Burden of interpandemic influenza in children younger than 5 years: a 25 -year prospective study. J Infect Dis, v. 185, p. 147-52, 2002.

22. ORGANIZAÇÃO MUNDIAL DA SAÚDE. CID-10. Classificação estatística internacional de doenças e problemas relacionados à saúde - $10^{a}$ revisão. Tradução do Centro Colaborador da OMS para a Classificação de Doenças em português. São Paulo: EDUSP, 1994. v. 1.

23. PIEDRA, A.; ENGLUND, J. A.; GLEZEN, W. P. Respiratory syncytial virus and parainfluenza viruses. In: RICHMAN, D. D.; WHITLEY, R. J.; HAYDEN, F. G. (Ed). Clinical Virology. New York: Churchill Livingstone, 1997. p. 787-819.

24. PITREZ, P. M. C. et al. Rhinovirus and acute bronchiolitis in young infants. J Pediatr, v. 81, n. 5. p. 417-20, 2005.

25. PORTES, S. A. R. et al. Enteroviruses isolated from patients with acute respiratory infections during seven years in Rio de Janeiro (1985-1991). Rev Inst Med Trop São Paulo, v. 40, n. 6, p. 337-42, 1998.

26. RAY, G. C. et al. Acute lower respiratory illnesses during the first three years of life: potential roles for various etiologic agents. Pediatr Infect Dis J, v. 12, n. 1, p. 10-4, 1993.

27. SHETTY, A. K. et al. Comparison of conventional viral cultures with direct fluorescent antibody stains for diagnosis of community-acquired respiratory virus infections in hospitalized children. Pediatr Infect Dis J, v. 22, p. 789-94, 2003.

28. STEPHENS, P. R. S. et al. Human metapneumovirus detection in children with respiratory disease, without diagnostic for others respiratories virus. J Braz Soc Virol, v. 10, Suppl 1, p. 173, 2005.

29. STRALIOTTO, S. M. et al. Respiratory viruses in the pediatric intensive care unit: prevalence and clinical aspects. Mem Inst Oswaldo Cruz, v. 99, n. 8, p. 883-7, 2004.

30. STRALIOTTO, S. M. et al. Etiologia viral das infecções respiratórias agudas em Porto Alegre, RS, Brasil. Rev Soc Bras Med Trop, v. 35, n. 3, p. 283-91, 2002.

31. SUTMÖLLER, F. et al. Etiology of acute respiratory tract infections among children in a combined community 
and hospital study in Rio de Janeiro. Clin Infec Dis, v. 20, p. 854-60, 1995.

32. SUTMÖLLER, F. et al. Viral etiology of acute respiratory diseases in Rio de Janeiro: first two years of a longitudinal study. Bull World Health Organ, v. 61, n. 5, p. 845-52, 1983.

33. TEPER, A.; FISCHER, B. G.; JONES, M. H. Seqüelas respiratórias de doenças virais: do diagnóstico ao tratamento. J Pediatr, v. 78, Suppl 2, p. 187-94, 2002.

34. TSUCHIYA, L. R. R. V. et al. Viral respiratory infection in Curitiba, Southern Brazil. J Infect, v. 51, p. 401-7, 2005.

35. VAINIONPÄÄ, R.; HYYPIÄ, T. Biology of parainfluenza viruses. Clin Microbiol Rew, v. 7, n. 2, p. 265-75, 1994.
36. VIEIRA, S. E. et al. Clinical patterns and seasonal trends in respiratory syncytial virus hospitalizations in São Paulo, Brazil. Rev Inst Med Trop São Paulo, v. 43, n. 3, p. 125-31, 2001.

37. WANG, E. E. L. et al. PICNIC (Pediatric Investigators Collaborative Network on Infections in Canada) study of the role of age and respiratory syncytial virus illness in patients with underlying heart or lung disease. 1997. Pediatrics (serial on-line). Disponível em: <http://www. pediatrics.org>. Acesso em: 22 ago. 2005.

38. XEPAPADAKI, P. et al. Human metapneumovirus as a causative agent of acute bronchiolitis in infants. J Clin Virol, v. 30, p. 267-70, 2004. 